\title{
Os saberes ensinados nas aulas de produção do gênero resumo
}

\author{
The knowledge taught in classrooms of summary writing genre \\ Márcia Andréa Almeida de Oliveira \\ Luana Aquino da Costa
}

Universidade Federal do Pará - UFPA - Pará - Brasil

\begin{abstract}
Resumo: Neste artigo, descrevemos aulas do gênero resumo, ministradas por um professor do 9 ano, de uma escola privada de Belém, com vistas a investigar que dimensões do gênero resumo são ensinadas, bem com a analisar se a forma como elas são didatizadas permite aos alunos se apropriar dos conteúdos e dos saberes ensinados referentes ao gênero-alvo. Como metodologia, adotamos a abordagem qualitativa de pesquisa e realizamos um estudo de caso, a fim de observar, compreender e interpretar as práticas de ensino de um professor. Para a análise dos dados, baseamo-nos nos estudos sobre gênero textual, sequência didática e escrita. Com base na análise das aulas, observamos que o grande desafio que se impõe à didatização de gênero na escola é a mudança na abordagem teórico-metodológica utilizada para tratar o objeto de ensino.
\end{abstract}

Palavras-chave: Resumo; Ensino-aprendizagem da escrita; didatização de gêneros textuais.

Abstract: In this article, we describe classes of the summary genre taught by a 9th grade teacher, from a private school located in Belém, in order to investigate which dimensions of the summary genre are taught, and to analyze if the way in which they are pedagogized allows students to acquire the contents and knowledge taught concerning the target genre. Regarding the methodology, we adopted the qualitative research approach, and we did a case study in order to observe, understand and interpret the teaching practices of a teacher. For the analysis of the data, our studies were based on textual genre, didactic sequence and written production. Based on the analysis of the classes, we observed that the great challenge that is imposed to the gender pedagogization in school is the change in the theoretical-methodological approach used to treat the teaching object.

Keywords: Summary; Teaching and learning of the writing process; pedagogization of textual genres. 


\section{Introdução:}

Vivemos em uma sociedade letrada, na qual a escrita está presente nas mais diversas atividades que realizamos diariamente, sejam essas relacionadas ao trabalho, à família ou à escola. Visivelmente, ela possui caráter funcional para nós, pois através dela opinamos, comentamos, explicamos, compartilhamos conhecimentos e informações. A escrita "[...] na diversidade de seus usos, cumpre funções comunicativas socialmente específicas e relevantes" (ANTUNES, 2003, p. 48).

As pessoas escrevem textos em situações informais para interagir com o outro, por exemplo, enviam mensagens instantâneas, fazem posts em redes socais e deixam bilhetes na porta da geladeira. Elas também escrevem em situações formais, por exemplo, enviam e-mails aos clientes, elaboram relatórios e atas de reunião, dentre outras possibilidades. Todas essas formas de interação se manifestam por meio de gêneros textuais. Segundo Schneuwly e Dolz (2004), os gêneros assumem um papel muito importante no ensino de línguas, já que representam uma forma de articulação entre as práticas sociais de referência ${ }^{1}$ e os objetos escolares; sendo o conhecimento do gênero necessário para a produção escrita, pois quando escrevemos mobilizamos saberes para organizar o texto, tanto relativamente a sobre o que dizer, quanto ao modo como se pode dizer.

Embora a escrita faça parte das atividades realizadas cotidianamente, muitas pesquisas têm mostrado a grande dificuldade que os alunos têm de produzir textos adequados às características do gênero textual ${ }^{2}$ escritos conforme as regras de escrita (ortografia, norma-padrão, textualidade). Relacionadas a essas discussões, os estudiosos mostram o desânimo dos professores, que reclamam

\footnotetext{
1 Com relação a esse termo, podemos destacar que são "atividades objetivas de transformação de um dado natural ou humano ('prática')", que são "o conjunto de um setor social, e não [os] papéis individuais ('social')" e que "a relação com as atividades didáticas não é de identidade, ela existe somente em termos de comparação ('referência')" (MARTINAND, 1986, p. 137).

${ }^{2}$ Neste trabalho, refletimos sobre o gênero e o seu ensino a partir dos estudos do Interacionismo Sociodiscursivo (BRONCKART, 2007).
}

da falta de habilidade dos alunos para escrever, e o tratamento inadequado que a atividade de produção escrita tem recebido nos ambientes educacionais. Essa inadequação vai desde a manutenção da tradição dos tipos textuais (narração, dissertação e descrição; esses considerados por Schneuwly e Dolz (2004) como gêneros escolares) até a ausência de exercícios de produção escrita. A prioridade em se trabalhar ainda hoje os tipos textuais é reforçada, no contexto brasileiro, pelo Exame Nacional do Ensino Médio (Enem), cujo foco é a produção de um texto dissertativo-argumentativo. Ao priorizar o "gênero escolar" dissertação, a proposta acaba contribuindo para que o gênero não seja tematizado como uma forma de comunicação, pois ele aparece desprovido de qualquer relação com uma situação de comunicação. Sobre a presença da redação escolar (materializada na forma de narração, dissertação e descrição), Geraldi (1997) destaca que ela é uma atividade que, em geral, é realizada sem nenhum propósito claro, não tendo significado para os alunos, uma vez que não lhes é proporcionado levar em consideração a situação de comunicação, o que resulta em um "falseamento" dessa atividade e em uma tarefa usada para corrigir ortografia e "erros" gramaticais.

Assim, com base na problemática em torno do ensino de gêneros escritos, neste artigo, descrevemos as aulas de produção escrita do gênero resumo, com vistas a investigar quais as dimensões desse objeto são ensinadas, bem como a analisar se a forma como o gênero é didatizado permite aos alunos se apropriar dele. Para tanto, baseamo-nos em estudos sobre o ensino da escrita (GERALDI, 1997; ANTUNES, 2003) e em reflexões a respeito dos gêneros textuais (BAKHTIN, 1997, SCHNEUWLY; DOLZ, 2004, PASQUIER; DOLZ, 2002).

Para dar conta de nosso objeto de estudo, na seção 2, discorremos sobre os gêneros textuais, buscando destacar o que eles são e suas características principais, como também os princípios que norteiam o seu ensino. $\mathrm{Na}$ seção 3, apresentamos informações sobre a escrita, com vistas a esclarecer o tratamento que ela recebe no contexto de ensino brasileiro; na seção 4, 
descrevemos a metodologia de pesquisa uitlizada e, na seção 5, refletimos sobre o ensino do gênero resumo em uma turma do Ensino Fundamental II, mostrando que o trabalho com a escrita se organiza em torno de conteúdos conceituais e discutindo o efeito do método expositivo na apropriação do gênero resumo pelo aluno.

\section{0 ensino de gêneros textuais}

Neste tópico, vamos enfocar as discussões sobre gênero e o seu ensino de acordo com o grupo de pesquisa "Didática das línguas e formação de professores: análise do francês ensinado (Grafe) ${ }^{3 ",}$, que tem influenciado o ensino da língua portuguesa, como é possível observar nas pesquisas realizadas sobre o tema (cf. ROJO, 2001, GUIMARÃES, 2006, GOMES-SANTOS; SEIXAS, 2012, NASCIMENTO, GONÇALVES; SAITO, 2007), nas alusões feitas ao trabalho do grupo no material das Olimpíadas de Língua Portuguesa, nos Parâmetros Curriculares Nacionais (BRASIL, 1998) e, ainda, embora de forma indireta, na Base Nacional Comum Curricular de Língua Portuguesa (BRASIL, 2017), a qual propõe o tratamento do texto com base no gênero a que pertence.

Antes de discorrermos sobre gênero de texto, é importante destacar que a discussão da noção de gênero foi inicialmente estabelecida por Bakhtin (1997), que afirma serem os gêneros formas do discurso que possuem determinadas características e parâmetros comuns, que emergem das inúmeras esferas da atividade humana e se configuram de acordo com a finalidade e a especificidade de cada uma. Segundo o autor, os gêneros são constituídos socialmente e "organizam nossa fala da mesma maneira que a organizam as formas gramaticais (sintáticas). Aprendemos a moldar nossa fala às formas do gênero e, ao ouvir a fala do outro, sabemos de imediato, bem nas primeiras palavras, pressentirIhe o gênero" (BAKHTIN, 1997, p. 302).

Ainda de acordo com Bakhtin (1997, p. 279), os gêneros discursivos são "tipos relativamente

\footnotetext{
${ }^{3}$ Didactique des langues et formation des enseignants : analyse du français enseigné (Grafe).
}

estáveis de enunciados" que refletem as condições de produção e as finalidades do campo da atividade humana, sendo constituídos por três elementos: conteúdo temático, forma composicional e estilo (meios fraseológicos, gramaticais e lexicais, cujas escolhas dependem de uma determinada situação de comunicação). O conteúdo temático não diz respeito ao assunto do texto, mas ao domínio de que se ocupa o gênero, ou seja, ao que é possível dizer por meio dele; a construção composicional reflete a forma como o texto é estruturado e moldado; o estilo corresponde às escolhas lexicais, ao tipo de linguagem utilizado para a construção do texto, uma linguagem mais objetiva ou subjetiva, um registro mais formal ou informal, etc. Ao discorrer sobre as características do gênero, Fiorin (2006) menciona, por exemplo, que as cartas de amor configuram o tema das relações amorosas (conteúdo temático); trazem a indicação do local, a data em que foram escritas, o nome do interlocutor e, quando não anônimas, o nome de quem escreve (construção composicional); e podem ser mais objetivas e informais (estilo).

Nas publicações do grupo Grafe, encontramos uma releitura das proposições sobre gênero de Bakhtin. Schneuwly e Dolz (2004, p. 74, grifo dos autores), com base nos estudos bakhtinianos, vinculam a reflexão sobre gênero às noções de práticas de linguagem e atividades de linguagem", afirmando que "é através dos gêneros que as práticas de linguagem materializam-se nas atividades dos aprendizes". Os autores propõem a noção de gênero textual como meio de articulação entre as práticas sociais e os objetos escolares, sendo eles, ao mesmo tempo, instrumentos de comunicação e objetos de ensino, funcionando como uma interface entre locutor e interlocutor nas situações de comunicação e como princípios organizadores dentro do trabalho didático. Para os autores, o trabalho escolar se faz sobre os gêneros, que se constituem em "instrumento de mediação de toda estratégia de ensino e material de trabalho,

\footnotetext{
4 "A primeira [prática de linguagem] fornece um ponto de vista contextual e social das experiências humanas [...]" e "a segunda [atividade de linguagem] adota um ponto de vista psicológico para dar conta dos mecanismos de construção interna dessas experiências [...]" (SCHNEUWLY; DOLZ, 2004, p. 72).
} 
necessário e inesgotável, para o ensino da textualidade" (SCHNEUWLY; DOLZ, 2004, p. 51).

Com relação ao ensino-aprendizagem de gênero, Schneuwly (2004, p. 144) discorre sobre a ficcionalização, processo que envolve a representação abstrata da situação. Segundo ele "a modelização dessa representação isola quatro parâmetros da produção: enunciador, destinatário, finalidade ou objetivo, lugar social.". Esses elementos, mesmo que de forma ficcionalizada, devem aparecer no processo de produção, porque servem para guiar os escreventes. De acordo com Dolz, Schneuwly e Haller (2004, p. 172), "o trabalho sobre os gêneros dota os alunos de meios de análise das condições sociais efetivas de produção e de recepção dos textos" e permite que o professor proponha atividades específicas que contribuam para o desenvolvimento da proficiência em escrita dos estudantes.

Ainda a respeito do trabalho sobre o gênero, Dolz e Schneuwly (1998) e Schneuwly e Cordeiro (2016) afirmam que a análise das características do gênero fornece uma primeira base para a organização das atividades de ensino. Eles sugerem assim que sejam construídos modelos didáticos de gêneros e, com base nestes, elaboradas sequências didáticas. De acordo com De Pietro e Schneuwly (2006, p. 34), o modelo didático apresenta duas características: "Ele permite construir, para um mesmo público-alvo, atividades de ensinoaprendizagem diversas" e "permite construir sequências de ensino-aprendizagem de complexidade crescente e conforme o desenvolvimento dos aprendentes". Para servir de ferramenta para a construção de sequências didáticas, o modelo precisa explicitar cinco componentes: a definição geral do gênero; os parâmetros do contexto comunicativo; os conteúdos específicos; a estrutura textual global; e as operações linguageiras e suas marcas linguísticas (DE PIETRO; SCHNEUWLY, 2006), porque é com base nesses conhecimentos que o professor poderá elaborar atividades e tarefas diversas, organizadas em módulos, a fim de ajudar o aluno a dominar melhor o gênero-alvo.
Após a elaboração do modelo didático, passase então à produção da sequência didática, que corresponde a um "[...] conjunto de atividades escolares organizadas, de maneira sistemática, em torno de um gênero textual oral ou escrito" (DOLZ; NORREVAZ; SCHNEUWLY, 2004, 97). Trata-se de um dispositivo didático criado para viabilizar o trabalho do professor e que favorece aos alunos acessarem às práticas de linguagem, usarem a língua em diversas situações comunicativas e colocarem em prática os aspectos da linguagem já internalizados e aqueles sobre os quais ainda não têm domínio, possibilitando, dessa maneira, uma aprendizagem mais efetiva do objeto ensinado.

Esse dispositivo é composto pelas seguintes etapas: apresentação da situação, produção inicial, módulos e produção final, como mostra a Figura 1.

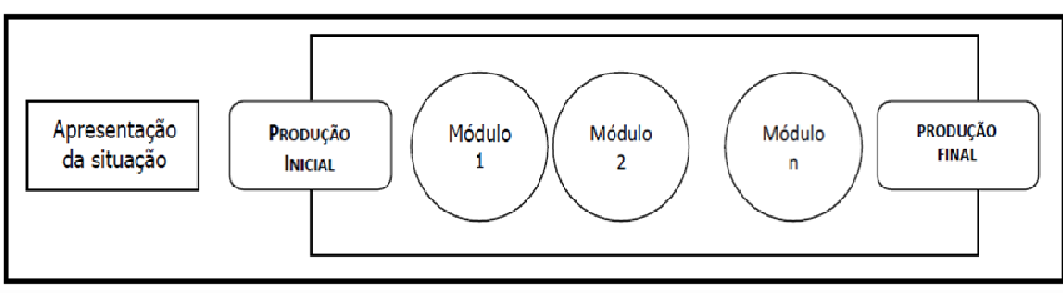

Figura 1 - As etapas da sequência didática, segundo Dolz, Noverraz e Schneuwly (2004, p. 98).

A apresentação da situação consiste na explicitação do projeto comunicativo, dos elementos da situação de conhecimento e na preparação dos conteúdos dos textos. A produção inicial é o momento em que os alunos tentam elaborar um primeiro texto do gênero-alvo. Os módulos correspondem ao momento em que se trabalham os problemas que apareceram na primeira produção e dá condição para que os alunos os superem. A produção final é o momento em que o aluno pode colocar em prática 0 que aprendeu durante os módulos e, a partir da qual, o professor pode ter uma visão dos avanços dos alunos.

Observamos assim que a sequência didática favorece que os gêneros textuais possam ser o ponto de partida e chegada do trabalho didático e se constituam em ponto de referência concreto para os alunos, possibilitando a estes o desenvolvimento de suas capacidades de linguagem e, ao mesmo tempo, a proposta de produção inerente à sequência requer 
deles "adaptar-se às características do contexto e do referente (capacidades de ação); mobilizar modelos discursivos (capacidades discursivas); dominar as operações psicolinguísticas e as unidades linguísticas (capacidades linguístico-discursivas)" (DOLZ; SCHNEUWLY, 2004, p. 52).

\section{Os gêneros textuais e a produção escrita}

Neste tópico, vamos discutir especificamente o ensino de gêneros textuais escritos, destacando aspectos específicos da escrita, já que ela envolve conhecimentos sobre o código da língua, a normapadão, o vocabulário, os gêneros textuais etc.

Como já dito por vários professores e pesquisadores, ensinar a escrever não é uma tarefa fácil. Trata-se de uma atividade complexa, que exige uma aprendizagem lenta e prolongada. É uma atividade que requer o investimento do professor na preparação de tarefas que promovam o desenvolvimento da habilidade de escrever dos alunos e na avaliação dos textos e na regulação das aprendizagens. Mas, qual é o espaço para essas atividades nas aulas de língua portuguesa?

Em relação às atividades de produção escrita realizadas na escola, Antunes (2003, p.25-27), esclarece que tais práticas, em geral, consistem em

- um processo de aquisição da escrita que ignora a interferência decisiva do sujeito aprendiz, na construção e na testagem de suas hipóteses de representação gráfica da língua.

- uma prática de uma escrita mecânica e periférica, centrada, inicialmente, nas habilidades motoras de produzir sinais gráficos e, mais adiante, na memorização pura e simples de regras ortográficas.

- uma prática de uma escrita artificial e inexpressiva, realizada em exercícios de criar listas de palavras soltas ou ainda, de formar frases [...].

- uma prática de uma escrita sem função, destituída de qualquer valor interacional, sem autoria e sem recepção (apenas para "exercitar") [...].

- uma prática, enfim, de uma escrita improvisada, sem planejamento e sem revisão, na qual o que conta é, prioritariamente, a tarefa de realizá-la não importa "o que se diga" e o "como se faz".

Ainda quanto ao trabalho com a escrita nas escolas, nos dias atuais, é recorrente a realização de atividades que se limitam apenas à produção de redações, que, por seu objetivo, não estão relacionadas ao uso real da língua, já que o único interlocutor previsto é o professor ou o corretor do Enem. Nessas práticas de ensino, as correções das produções dos alunos incidem, quase que exclusivamente, sobre aspectos relacionados à superfície textual, tais como: ortografia, acentuação e pontuação, e o conteúdo sobre o qual se escreve não é tido como relevante nem os elementos da textualidade. Em um ensino organizado em torno da tipologia e das regras gramaticais, o professor é o leitor e o corretor dos textos produzidos pelos alunos, não emitindo nenhum tipo de retorno acerca do conteúdo produzido e da textualidade. O aluno recebe a "folhinha de redação" e desenvolve um texto, que (ou quase nunca) será reescrito. Tal abordagem se afasta da abordagem de trabalho proposto por Dolz, Noverraz e Schneuwly (2004, p. 97), já que, segundo esses autores,"os textos escritos ou orais que produzimos diferenciam-se uns dos outros e isso porque são produzidos em condições diferentes”.

Sobre o ensino da escrita, Marcuschi (2010, p. 11) afirma que:

[...] no ensino da elaboração textual, devem ser propostas situações que se reportem a práticas sociais e a gêneros textuais passíveis de serem reconstituídos, ainda que parcialmente, em sala de aula, tanto no que se refere à produção quanto no que se refere à recepção do texto escrito. Escrever na escola, portanto, deve ser visto como um ensaio ou mesmo uma prévia convincente do que será requerido dos jovens aprendizes no espaço social.

Reconhecendo o papel dos gêneros textuais no ensino-aprendizagem da produção escrita, destacamos aqui a proposta defendida por Dolz, Noverraz e Schneuwly (2004), que consiste no uso de sequências didáticas como dispositivo didático para o ensino da escrita. Segundo Dolz e Schneuwly (2004), as sequências não só favorecem ao aluno aprender o sistema de escrita da língua e suas regras de funcionamento por meio de um ensino sistematizado, como também considerar a situação de comunicação a que o texto está vinculado durante a produção textual. Nessa abordagem, é levada em consideração 
a funcionalidade da escrita, com base no seu uso real. Ao se orientar por ela, o professor deixa de ser o único leitor, e os textos produzidos pelos alunos passam a ter outros interlocutores, que podem ser os colegas de turma, a comunidade escolar etc., porque a sequência didática prevê em seu cerne um projeto comunicativo, o qual vai orientar as ações dos alunos na escrita do texto do gênero-alvo. Além disso, o trabalho com gêneros orientado por sequências didáticas justifica-se, uma vez que o aluno vai ter oportunidade de escrever, focar em suas dificuldades (módulos) e reescrever o texto, buscando implementar os novos saberes aprendidos ou aqueles já consolidados.

Assim, no que diz respeito ao ensino de gêneros escritos, o papel da escola é dar condições, para que os discentes possam se apropriar deles, tal como destacam Schneuwly e Dolz (2004, p. 79): "trata-se de levar o aluno ao domínio do gênero, exatamente como este funciona (realmente) nas práticas de linguagem de referência.". Podemos afirmar, então, que é necessário que a escola proporcione o contato do aluno com diferentes gêneros e seja um espaço de aprendizagem, por exemplo, de notícias, anúncios publicitários, receitas, memes, artigos de opinião etc., porque essas formas medeiam as interações sociais diárias de toda a população. Logo, para que os sujeitos alunos possam participar de diferentes situações de comunicação, é necessário que eles sejam capazes de reconhecer, compreender e produzir diferentes gêneros.

Quanto especificamente ao ensino da escrita, para Pasquier e Dolz (2002, p. 01), o docente precisa conhecer "os instrumentos didáticos atualmente disponíveis" e ter "ideias claras sobre o ensino da produção escrita, de maneira que não se perca em atividades entediantes, repetitivas e desnecessárias e, sobretudo, pouco eficazes". Além disso, os autores destacam alguns princípios que norteiam o trabalho com a produção de texto escrito, devendo o professor considerá-los como constituintes do ensino e da aprendizagem da escrita. São eles:

\section{$A$ diversidade textual}

O ensino da produção escrita deve ser compreendido como um conjunto de aprendizagens específicas de variados gêneros textuais, e não como um procedimento único e global válido para qualquer texto, visto que cada texto apresenta problemas de escrita distintos que solicitam estratégias de ensino diferenciadas e adaptadas a eles.

\section{Aprendizagem precoce}

Considerando que a atividade de escrever é lenta e longa, é conveniente começar o ensino da escrita desde os primeiros anos da escolaridade. Mas, começar mais cedo não implica dizer que os alunos mais novos farão desde cedo as atividades previstas no currículo dos mais velhos e, sim, que as atividades aparecerão em todos os níveis de ensino, sugeridas de acordo com as potencialidades e dificuldades de aprendizagem dos alunos.

\section{$A$ aprendizagem em espiral}

A aprendizagem em espiral propõe uma progressão em curva ao invés de um ensino linear, baseado na tipologia textual, que vai da narração para a argumentação, passando pela descrição e exposição. A progressão em espiral consiste no ensino, em todos os níveis, da diversidade discursiva (narração, explicação, argumentação, descrição e diálogo), variando o gênero textual e as dimensões textuais estudadas.

\section{Começar com tarefas complexas}

Em vez de começar o processo de aprendizagem com atividades simples e somente depois passar para as atividades mais complexas, deve-se partir do complexo para o mais simples, para, ao final, voltar novamente ao mais complexo.

\section{Ensino intensivo}

As justificativas para um ensino intensivo dão-se por dois motivos: em primeiro lugar, porque, quando as atividades orientadas para um mesmo objetivo ocorrem diariamente, as perdas por esquecimento são menores e é possível estabelecer a continuidade na aprendizagem. Em segundo lugar, porque é necessário conscientizar o aprendente a respeito daquilo que ele faz e do objetivo pretendido. Se o tempo da atividade se estender muito, os alunos perdem o interesse e já não sabem o porquê de estarem fazendo a atividade proposta.

Textos sociais 
Apresentar aos alunos os textos ditos sociais e não textos forjados para a situação de ensino. É importante que o aluno não imite os textos escolares, mas tenha contato com textos usados em situações de comunicação reais.

\section{A revisão como atividade de aprendizagem}

Frequentemente, nas correções dos textos, os professores fazem comentários que, muitas vezes, não podem ser compreendidos pelos alunos, o que representa dificuldade na reescrita, o que acaba fazendo com que os alunos se concentrem na correção de erros de ortografia e de palavras. Assim, é importante que a revisão seja também objeto de aprendizagem, já que é uma atividade que está integrada à atividade de escrita. A revisão, a releitura e reescrita de um texto são atividades que também se aprendem e, por isso, devem ser focalizadas nas situações de ensino. Algumas estratégias podem ser adotadas pelo professor, como: permitir que o aluno se distancie do texto; fornecer instrumentos linguísticos sobre o gênero-alvo; desenvolver atividades que foquem as dimensões textuais que se apresentaram difíceis; discutir critérios de legitimidade e eficácia comunicativa etc. Ao realizar um trabalho dessa natureza, o aluno, ao final, não fará apenas a "limpeza do texto", mas terá consciência do que precisa melhorar para tornar o texto mais adequado às características do gênero e à situação de comunicação.

Método indutivo: a apropriação por parte do aluno

Para levar os alunos a superar as dificuldades apresentadas na aprendizagem da escrita, não é aconselhável expor itens gramaticais, como conjunções e advérbios, de forma conceitual, mas levar o aluno a perceber os seus usos por meio de atividades de observação, comparação e análise, a fim de que eles desenvolvam habilidades essenciais para a realização da tarefa, por exemplo, a de produção textual. Nesse caso, sugere-se a implementação do método indutivo em oposição ao ensino transmissivo, o que implica que sejam propostas observações de fenômenos e exercícios concretos, para levar os alunos a tomar consciência do funcionamento linguístico. Essa mudança implica elaborar exercícios de qualidade e decompor as dificuldades, para que se efetive a construção de capacidades comunicativas e linguístico-discursivas.

Regulação interna e externa

A avaliação formativa prevê a construção de instrumentos, como lista de controle com aspectos linguísticos, que promovam a regulação da aprendizagem da produção escrita. Esses instrumentos de regulação que, inicialmente, são externos, progressivamente, transformam-se em instrumentos de regulação interna. Orientando-se por essa abordagem, no trabalho com a escrita, é importante possibilitar ao aluno superar as dificuldades que encontra, por exemplo, na articulação das partes do texto e no encadeamento de palavras e frases, e assumir a postura de crítico de sua própria atividade, a fim de controlar e superar os problemas de escrita que surgirem.

\section{Sequências didáticas}

Os princípios destacados anteriormente concretizam-se na sequência didática, já que ela se caracteriza como um conjunto de atividades visando a que o aluno aprenda a escrever um determinado gênero textual. Trata-se de um dispositivo que favorece a identificação das dificuldades dos alunos por meio da primeira produção, o tratamento, de forma progressiva, dos problemas identificados (realizado nos módulos) e a tomada de consciência dos alunos quanto ao seu desenvolvimento.

A proposta de sequência didática vem de encontro, portanto, à ideia simplista de que basta propor atividades de redação para que os alunos, por "um toque de mágica", aprendam a escrever. O que fundamenta seu uso é o pressuposto de que os alunos podem aprender a escrever inúmeros textos de diferentes gêneros graças a um ensino sistemático, que acione instrumentos comunicativos e linguísticos.

Considerando todas as discussões aqui feitas, concluímos que a aprendizagem da escrita não é algo espontâneo, mas exige intervenção didática do professor, sendo esta mediada por dispositivos de ensino que possibilitem ao aluno se apropriar do sistema de escrita do português, das regras de funcionamento da língua e dos gêneros textuais. 
O pressuposto embasador das reflexões propostas a seguir é o de que o domínio do gênero favorece ao aluno participar de diferentes situações de comunicação e que a sequência didática é um dispositivo que pode viabilizar isso.

\section{Metodologia}

Para realizar o estudo, cujos resultados são aqui apresentados, desenvolvemos uma pesquisa qualitativa (LÜDKE; ANDRÉ, 1986), uma vez que enfocamos aspectos da realidade que não podem ser quantificados e buscamos descrever e analisar como um determinado professor conduz o ensino da produção do gênero resumo. Essa abordagem de pesquisa, de acordo com Godoy (1995), tem por objetivo traduzir e interpretar fenômenos sociais situados em um tempo-espaço determinado e produzir informações aprofundadas acerca de um determinado objeto de investigação.

Com vistas a alcançar os objetivos de pesquisa, fizemos também uso da pesquisa bibliográfica, pesquisa documental e estudo de caso. Bibliográfica, uma vez que, para nos situar em relação às discussões já existentes sobre o tema da pesquisa, fizemos levantamento de referenciais teóricos. Documental, porque fizemos análise dos resumos escritos pelos alunos, com a intenção de verificar que aspectos da escrita foram avaliados. Estudo de caso, pois nosso objeto de investigação são as aulas de um professor da turma do $9^{\circ}$ ano, de uma escola particular de Belém, cidade situada na região Norte do Brasil.

Durante o tratamento e análise de dados, fizemos uso da pesquisa explicativa (GIL, 2010), porque temos por objetivo explicitar o processo de didatização do gênero resumo e buscamos determinar fatores que podem ter influenciado a seleção das dimensões ensináveis.

Para a construção do corpus da pesquisa, valemo-nos da observação e de gravações em áudio de oito horas-aula, as quais são descritas na seção seguinte, ministradas por um professor, com quatro anos de experiência no ensino fundamental e formado pelo curso de Letras (Licenciatura em Língua
Portuguesa), da Universidade Federal do Pará, em cujo currículo consta da disciplina Oficina de didatização de gêneros textuais, a qual contempla em sua ementa o planejamento de sequências didáticas para o ensino de gêneros.

Além desses instrumentos, fotocopiamos as produções escritas (iniciais e finais) de quatro alunos para exemplificar as regulações que constavam nos textos e verificar os avanços na aprendizagem do gênero resumo. É importante mencionar que na análise priorizamos as aulas expositivas do professor sobre o gênero resumo, não contemplando, portanto, as produções escritas dos alunos neste artigo.

Os alunos participantes da pesquisa são oriundos da classe média de Belém e têm entre 13 e 15 anos. De um modo geral, durante o período de realização da sequência didática do gênero resumo, eles participaram das aulas e fizeram as atividades propostas.

\section{Gênero resumo: dimensões ensinadas}

A fim de verificar quais dimensões do objeto foram ensinadas, bem como compreender o processo de didatização do gênero resumo realizado pelo professor, organizamos e analisamos os dados com base nestas perguntas: Que dimensões do gênero foram objetos de ensino? Que dispositivo(s) didático(s) foi(ram) acionado(s) pelo professor durante as aulas? Que princípio metodológico foi adotado?

\subsection{0 modelo didático do gênero resumo escolar: uma síntese}

Segundo Machado, Lousada e Abreu-Tardelli (2005, p. 91), o resumo é:

[...] a apresentação concisa dos conteúdos de outro texto (artigo, livro, etc.), que mantém uma organização que reproduz a organização do texto original, com o objetivo de informar o leitor sobre esses conteúdos e cujo enunciador é outro que não o autor do texto original $[\ldots]$. 
Para construir um enunciado desse gênero, 0 escrevente precisa se ater às informações presentes no texto, isto é, não pode acrescentar informações nem opinar sobre o que foi discutido no texto-base, e mobilizar estratégias de apagamento (apagamento de conhecimentos inferíveis, de expressões que indicam sinonímia ou explicação, de exemplos, de justificativas de afirmações, de argumentos contra a posição do autor), de generalização (que consiste na substituição de nomes por termos mais genéricos) e de construção (que consiste na substituição de uma sequência de afirmações por uma única proposição).

Além dessas características, o gênero resumo escolar apresenta outras, que são elencadas no Quadro 1.

\begin{tabular}{|c|c|}
\hline \multicolumn{2}{|c|}{ Modelo didático do gênero resumo escolar } \\
\hline $\begin{array}{l}\text { Parâmetros do } \\
\text { contexto } \\
\text { comunicativo }\end{array}$ & $\begin{array}{l}\text { Locutor: em geral, aluno ou acadêmico, } \\
\text { que tem consciência de que o professor } \\
\text { tem por objetivo realizar uma avaliação. } \\
\text { Interlocutor previsto: em geral, professor. } \\
\text { Finalidade: sintetizar as principais } \\
\text { informações de um texto. } \\
\text { Esfera: escolar e acadêmica }\end{array}$ \\
\hline $\begin{array}{l}\text { Conteúdo } \\
\text { específico }\end{array}$ & $\begin{array}{l}\text { Autor do texto original; função social do } \\
\text { autor; suporte onde o texto foi publicado; } \\
\text { momento possível da produção; objetivo } \\
\text { do autor do texto; tema do texto; } \\
\text { informações mais relevantes. }\end{array}$ \\
\hline $\begin{array}{c}\text { Estrutura } \\
\text { textual global }\end{array}$ & $\begin{array}{l}\text { Plano textual global: em geral, apresenta } \\
\text { título (referência bibliográfica do texto a } \\
\text { ser resumido ou apenas o nome da obra } \\
\text { e seu autor) e pode ser constituído de um } \\
\text { ou mais parágrafos. } \\
\text { Tipo de discurso mais comum: discurso } \\
\text { expositivo teórico (sem marcas de quem } \\
\text { fala). } \\
\text { Tipo de sequência predominante: } \\
\text { sequência explicativa. }\end{array}$ \\
\hline $\begin{array}{l}\text { Operações } \\
\text { linguageiras e } \\
\text { suas marcas } \\
\text { linguísticas }\end{array}$ & $\begin{array}{l}\text { Pontuação: comum do texto expositivo, } \\
\text { como ponto, vígula e dois pontos. } \\
\text { Organizadores textuais: } \\
\text { predominantemente, de adição, de } \\
\text { explicação, de oposição e de tempo. } \\
\text { Uso de verbos discendi: afirmar, dizer, } \\
\text { declarar, explanar etc. } \\
\text { Registro formal da língua portuguesa. } \\
\text { Uso da } 3^{\text {a }} \text { pessoa. } \\
\text { Tempo de ancoragem: presente } \\
\text { Vozes enunciativos: voz do autor do texto } \\
\text { resumido. } \\
\text { Linguagem objetiva. } \\
\text { Retomadas textuais: em geral, feitas por } \\
\text { pronomes e por nomes. }\end{array}$ \\
\hline
\end{tabular}

Quadro 1 - Modelo didático do gênero resumo escolar.

Fonte - As autoras.

\subsection{0 ensino do gênero resumo escolar}

Com base nos dados coletados, organizamos as aulas em cinco momentos, conforme o foco de cada uma: atividade na biblioteca; aula expositiva sobre o gênero resumo; atividade com os resumos produzidos; entrega dos resumos; e exposição do resumo. No Quadro 1, apresentamos as etapas da sequência de ensino ${ }^{5}$ implementada pelo professor.
5 Usamos o termo sequência de ensino, porque o trabalho
realizado pelo professor não foi estruturado em torno das
etapas da sequência didática proposta por Dolz, Noverraz e Schneuwly (2004). 


\begin{tabular}{|c|c|}
\hline Etapas & Atividades \\
\hline $\begin{array}{l}\text { Primeira } \\
\text { etapa: } \\
\text { atividade na } \\
\text { biblioteca }\end{array}$ & $\begin{array}{l}\text { Professor pede aos alunos que } \\
\text { selecionem um livro na biblioteca e façam } \\
\text { um fichamento, no qual destaquem as } \\
\text { seguintes informações: título do livro, } \\
\text { nome do autor, localização na biblioteca } \\
\text { (literatura, ciências, meio ambiente etc.), } \\
\text { número de páginas do livro, ano de } \\
\text { publicação e assunto tratado. }\end{array}$ \\
\hline $\begin{array}{l}\text { Segunda } \\
\text { etapa: aula } \\
\text { expositiva } \\
\text { sobre o } \\
\text { gênero } \\
\text { resumo }\end{array}$ & $\begin{array}{l}\text { Professor expõe o calendário de } \\
\text { atividades a serem realizadas pelos } \\
\text { alunos, dentre elas, a socialização da } \\
\text { leitura que eles estavam fazendo. } \\
\text { Relembra os alunos de que eles } \\
\text { precisam fazer o resumo do livro } \\
\text { selecionado e faz uma breve explicação } \\
\text { sobre o que é resumir. } \\
\text { Expõe que resumo é um texto impessoal } \\
\text { e que ele aparece em outros textos. } \\
\text { Apresenta um trecho de resumo, que ele } \\
\text { havia retirado de um material didático, } \\
\text { mas não chega a se alongar nele, porque } \\
\text { ele continha problemas de natureza } \\
\text { textual. } \\
\text { Explica que o resumo tem de ser menor } \\
\text { do que o texto-base. } \\
\text { Enfatiza que é preciso priorizar o uso da } \\
\text { terceira pessoa e da norma padrão e } \\
\text { usar conectores ao se redigir um texto. } \\
\text { Destaca quais informações devem } \\
\text { constar no resumo, como título, autor, } \\
\text { tema, e que não se deve acrescentar } \\
\text { informação, apenas colocar a essência } \\
\text { do texto. } \\
\text { Solicita que os alunos produzam o } \\
\text { resumo da explicação dele e entreguem- } \\
\text { no ao final da aula. Essa produção não } \\
\text { se caracteriza como primeira produção } \\
\text { na sequência realizada. Trata-se de uma } \\
\text { atividade extra. } \\
\text { Após perguntas dos alunos, apresenta } \\
\text { algumas estruturas que podem ser } \\
\text { usadas no resumo, como "segundo } \\
\text { informações que foram passadas aqui" e } \\
\text { "segundo o professor". }\end{array}$ \\
\hline $\begin{array}{c}\text { Terceira } \\
\text { etapa: } \\
\text { atividade com } \\
\text { os resumos } \\
\text { produzidos }\end{array}$ & $\begin{array}{l}\text { Professor recolhe os resumos dos livros } \\
\text { (primeira produção). } \\
\text { Escreve no quadro critérios avaliativos, } \\
\text { por exemplo: } \\
\text { "I. O texto apresenta uma leitura global } \\
\text { do livro? É possível perceber do que se } \\
\text { trata o livro? }(2,0) \\
\text { II. O texto é claro e compreensível }(2,0) \\
\text { III. Quanto à linguagem está apropriado } \\
\text { para uma produção escolar? (2,0) } \\
\text { IV. Há indicação da fonte do texto original } \\
\text { (2,0)" } \\
\text { Solicita aos alunos que não fizeram o } \\
\text { resumo que o façam em sala de aula. } \\
\text { Entrega o resumo da aula (solicitado na } \\
\text { segunda etapa) e pede aos alunos que } \\
\text { refaçam a atividade. } \\
\text { Explica a forma como os resumos estão } \\
\text { sendo avaliados, comentando os critérios } \\
\text { de avaliação expostos no quadro. } \\
\text { Redistribui os resumos dos livros que os } \\
\text { alunos haviam entregado, de forma }\end{array}$ \\
\hline
\end{tabular}

\begin{tabular}{|c|c|}
\hline & $\begin{array}{l}\text { aleatória, entre eles. } \\
\text { Pede que avaliem o texto do colega, de } \\
\text { acordo com os critérios indicados, e } \\
\text { atribuam a ele uma nota. } \\
\text { Alunos perguntam ao professor o que } \\
\text { seria uma leitura global; outros } \\
\text { perguntam como avaliar a linguagem; e } \\
\text { alguns reclamam dizendo "eu não sei } \\
\text { avaliar isso". } \\
\text { Professor caminha pela sala auxiliando } \\
\text { os alunos que têm dúvidas e } \\
\text { questionando os que não estão fazendo } \\
\text { a avaliação do texto do colega. } \\
\text { Ao final da aula, o professor pede que } \\
\text { entreguem a tarefa. }\end{array}$ \\
\hline $\begin{array}{c}\text { Terceira } \\
\text { etapa: } \\
\text { atividade com } \\
\text { os resumos } \\
\text { produzidos }\end{array}$ & $\begin{array}{l}\text { Professor recolhe os resumos dos livros } \\
\text { (primeira produção). } \\
\text { Escreve no quadro critérios avaliativos, } \\
\text { por exemplo: } \\
\text { "I. O texto apresenta uma leitura global } \\
\text { do livro? É possível perceber do que se } \\
\text { trata o livro? (2,0) } \\
\text { II. O texto é claro e compreensível (2,0) } \\
\text { III. Quanto à linguagem está apropriado } \\
\text { para uma produção escolar? (2,0) } \\
\text { IV. Há indicação da fonte do texto } \\
\text { original (2,0)" } \\
\text { Solicita aos alunos que não fizeram o } \\
\text { resumo que o façam em sala de aula. } \\
\text { Entrega o resumo da aula (solicitado na } \\
\text { segunda etapa) e pede aos alunos que } \\
\text { refaçam a atividade. } \\
\text { Explica a forma como os resumos estão } \\
\text { sendo avaliados, comentando os critérios } \\
\text { de avaliação expostos no quadro. } \\
\text { Redistribui os resumos dos livros que os } \\
\text { alunos haviam entregado, de forma } \\
\text { aleatória, entre eles. } \\
\text { Pede que avaliem o texto do colega, de } \\
\text { acordo com os critérios indicados, e } \\
\text { atribuam a ele uma nota. } \\
\text { Alunos perguntam ao professor o que } \\
\text { seria uma leitura global; outros } \\
\text { perguntam como avaliar a linguagem; e } \\
\text { alguns reclamam dizendo "eu não sei } \\
\text { avaliar isso". } \\
\text { Professor caminha pela sala auxiliando } \\
\text { os alunos que têm dúvidas e } \\
\text { questionando os que não estão fazendo } \\
\text { a avaliação do texto do colega. } \\
\text { Ao final da aula, o professor pede que } \\
\text { entreguem a tarefa. }\end{array}$ \\
\hline
\end{tabular}

Quadro 2- Atividades da sequência de ensino do gênero resumo.

Fonte - As autoras.

\section{Considerando essas informações e o princípio} teórico-metodológico assumido neste artigo, na seção seguinte, fazemos uma reflexão sobre as dimensões do objeto ensinadas pelo professor e a organização da sequência implementada, bem como sobre a abordagem metodológica que orientou o fazer docente. 


\subsection{Objetos ensinados nas aulas do gênero resumo escolar}

Nesta seção, buscamos evidenciar que aspectos do gênero resumo foram contemplados durante a sequência de ensino e analisar de que forma 0 trabalho proposto contribuiu para a apropriação do referido gênero pelos alunos.

\subsubsection{Os componentes do gênero}

Os componentes do gênero foram tratados na etapa 2, durante a qual o professor utilizou slides para apoiar sua explicação sobre aspectos referentes à definição, ao conteúdo e à linguagem do gênero.

Segundo Dolz, Schneuwly e Haller (2004, p. 171), aprender a escrever ou falar é apropriar-se de gêneros textuais, é dominar as suas dimensões essenciais, a saber: "os conteúdos que se tornam dizíveis por meio dele"; "a estrutura comunicativa"; "as configurações específicas das unidades linguísticas: traços da posição enunciativa do enunciador, conjunto particulares de sequências textuais e tipos de discurso que formam sua estrutura [...]".

Partindo desse pressuposto, analisamos a sequência, buscando verificar se esses elementos foram tratados e de que maneira foram didatizados. Assim, destacamos na nossa reflexão três aspectos: situação de comunicação (autor, suporte, finalidade, interlocutor, esfera), conteúdo e linguagem.

\section{Foco na situação de comunicação}

No que diz respeito à solicitação da produção de resumo, o professor a fez sem esclarecer os elementos da situação de comunicação. Mencionou apenas, na primeira etapa, que os alunos iriam ler um livro para produzir um resumo e, na segunda, que eles iriam socializar a leitura feita, como é possível verificar neste trecho da aula.

Professor: doze... nós vamos conversar sobre os trabalhos e organizar essa socialização dos livros de vocês que ocorrerá no dia dois de junho... aí para encerramento das atividades...

Durante a apresentação da tarefa, o professor não explicita, por exemplo, com que finalidade os alunos iriam fazer o resumo, quem seria o possível leitor do texto e onde esse texto iria circular; aspectos esses que servem para guiar o leitor na produção escrita, como destaca Marcuschi (2010, p. 12):

[...] é fundamental que o contexto de produção seja devidamente explicitado, no que tange ao objetivo pretendido (qual a razão da escrita?), ao espaço de circulação (em que âmbito o texto será divulgado?), ao leitor presumido (quem o escritor tem em mente, ao produzir seu texto?), ao suporte pressuposto (em que suporte o texto será disponibilizado?, ao tom que será assumido (formal ou informal?; irônico ou amigável?; próximo ou distante?) [...]

$\mathrm{Na}$ falta dessas informações, a atividade de linguagem proposta aparece descontextualizada e como mera tarefa de preenchimento de folha de papel em branco, um mero exercício escolar. Os alunos deixam assim de ter uma visão, embora fictícia, da situação de produção do resumo.

Será que assim 0 aluno conseguiria compreender a funcionalidade e o meio de circulação desse gênero, e assim, poderia se apropriar do objeto de ensino? De acordo com Schneuwly e Dolz (2004), é de suma relevância que no ensino de qualquer gênero sejam considerados não só os elementos relacionados às peculiaridades linguísticas e estruturais, como também as funções comunicativas, uma vez que a funcionalidade dos gêneros é o aspecto que influencia na escolha dos conteúdos, da estrutura e dos recursos linguísticos a serem mobilizados. Ainda na acepção dos autores, os gêneros assumem a função de "reguladores" no momento da produção escrita ou oral. A não consideração dos elementos da situação de comunicação implicou perda de referencial por parte do aluno, que acabou fazendo um texto que não atendia aos pré-requisitos do gênero.

Foco no conteúdo

Como afirmam Schneuwly e Dolz (2004), todo gênero se caracteriza pelos conteúdos e os conhecimentos que se tornam dizíveis por meio dele. No caso dos conteúdos do gênero resumo, observamos que em vários momentos o professor faz menção a eles, como os trechos da aula abaixo confirmam: 
Professor: [...] o resumo... na prática... ele é um / um intertexto... não é isso?! você precisa de um outro texto para escrever o seu próprio /... aí nós vamos... eh... tentar... tentar não... nós vamos discutir um pouco...eh... sobre isso... que algumas pessoas entendem que resumo é você sair cortando... não é isso?! pedaços do texto... não É isso... o resumo é um texto autorA:I... e (a) única diferença... é que ele pa:rte de um outro texto que realmente precisa ser fiel as ideias desse texto original... você não vai colocar nada de (diferente) do que está lá... [...]

Professor: [...] é a partes principais de outro texto fonte... por isso é um texto impessoal...isso significa que não é um texto que você VA:i apresentar as suas impressões ( ) no texto... ok?! a sua função aqui não é falar bem... falar mal de nada... é falar exatamente aquilo que acontece no texto... [...].

Professor: [...] ... então você pode iniciar fazendo um parágrafo de (introdução) olha... introdutório para contextualizar o leitor...quando eu falo contextualizar... é situar o leitor... sobre título... o autor... as informações pra que ele saiba sobre que texto você está falando... indique o texto literário resumindo o autor... algumas informações relevantes sobre o seu perfil... o tema... se ele é destinado para adolescentes... se ele é destinado para pais de família... para professores... você apresenta essas informações sobre o texto aí... apresentamos o texto... o título... o autor... a fonte... não é isso? de onde ele foi retirado... nesse caso aí... vocês estarão falando de um livro... né isso? então você vai falar do autor... e o título do livro... [...]

Observamos que, ao longo da explicação, o professor informa que os alunos deverão escrever um parágrafo introdutório para contextualizar o leitor, deverão indicar o texto resumido, o autor e o tema tratado, mas não chega a mostrar como elaborar esse parágrafo introdutório, nem apresenta exemplos de resumos que tenham circulado em situações reais de comunicação. Ele apenas menciona que essas informações deverão aparecer e usa como exemplo um resumo com problemas, os quais foram, inclusive, identificados pelos alunos.

$\mathrm{Na}$ atividade realizada na biblioteca, o professor também chama a atenção dos alunos para o conteúdo específico do gênero resumo, pois explica que eles devem fazer uma atividade, denominada por ele de "fichamento", que consistia na coleta de informações, a partir do livro escolhido, e copia na lousa o que deveria ser o foco de atenção dos alunos.

Título do livro

\author{
Autor/autores \\ Localização na biblioteca (literatura, ciências, \\ meio ambiente etc.) \\ Assunto do livro (verificar o assunto) \\ Número de páginas \\ Ano de publicação
}

Considerando o que foi realizado nessa atividade, infere-se que o propósito era mostrar aos alunos alguns dos elementos básicos que constituem o texto do gênero resumo, o que é bastante relevante. Entretanto, em nenhum momento, o professor destaca que as informações coletadas deveriam ser utilizadas por eles na produção do resumo, por exemplo, no início do texto. Observamos assim a necessidade da implementação de práticas de ensino que interliguem as diferentes etapas de uma sequência de ensino e que envolvam a elaboração de atividades sistemáticas sobre os objetos ensináveis do gênero, de modo a viabilizar a aprendizagem dos alunos.

Com base no que foi realizado em sala de aula, verificamos que os alunos têm acesso a algumas informações que devem aparecer em um resumo, contudo essas raramente aparecem nos textos dos alunos, nos quais identificamos adição de informação, presença de opinião, não indicação do autor e nome da obra. Assim, o tratamento didático dado ao resumo mostra a maneira como os gêneros vêm sendo tratados nos ambientes educacionais $\mathrm{e}$ confirma o que Machado, Lousada e Abreu-Tardelli (2005) dizem a esse respeito, isto é, que o gênero acaba sendo muito mais um artefato imposto ao trabalho do professor, do que um instrumento que possibilita a ação e a apropriação dos alunos. Além disso, a abordagem do gênero feita não possibilita a apropriação desse instrumento nem 0 desenvolvimento de capacidades de linguagem diversas, uma vez que o docente, durante as aulas, foca o saber sobre e não o saber fazer. Nesse sentido, supomos que a habilidade de escrita seria desenvolvida pela aquisição de conteúdo.

Foco na linguagem

A linguagem foi outro aspecto tratado nas aulas de produção do gênero resumo. Na segunda etapa, o professor expõe, por meio de um slide intitulado "linguagem", a necessidade de o resumo ser 
escrito em uma linguagem clara, sintética e objetiva, na terceira pessoa e na norma-padrão. Mas, como no aspecto anterior, não chega a propor atividades de observação e análise sobre os tópicos abordados.

Professor: lembra da linguagem... é uma:..... é uma preocupação (incompreensível) sintética... objetiva das ideias... de um texto... de modo que apenas aspectos mais relevantes... aí foi isso que eu falei pra vocês... os aspectos mais relevantes sejam apresentados... dar preferên::cia... né isso... pra linguagem... é preciso dar preferência ao uso da terceira pessoa... COMO foi o caso:.: dess/ porque que eu não devo utilizar gente... primeira pessoa no resumo...

Aluno 6: (incompreensível)

Professor: Estou falando de uma outra pessoa...

Aluno 8: (incompreensível)

Aluno 7: Porque tem intertextualidade

Professor: É por causa da intertextualidade que nós havíamos falado... essa primeira pessoa... a TENDÊN::CIA... que quando eu escrevo em primeira pessoa estar a transparecer as minhas impressões sobre aquele outro texto... né isso... e como o resumo trata-se de um texto impessoal eu devo evitar... então eu vou priorizar a terceira pessoa...

Como podemos constatar, embora 0 professor apresente características linguísticas do gênero resumo, a maneira como ele 0 faz praticamente não favorece ao aluno reunir as informações apresentadas e convertê-las em ação, isto é, na escrita do texto.

O professor também chama a atenção para o caráter objetivo do gênero ensinado. Mas, o exemplo utilizado são frases isoladas (transcritas abaixo), em vez de textos. Vale mencionar que, ao apresentá-las, ele apenas lê e lhes diz que, para sintetizar, foi feito o apagamento de informações desnecessárias para a compreensão do leitor.

Ex.: O velho jardineiro trabalhava muito bem. Ele arrumava muitos jardins diariamente. $\mathrm{O}$ jardineiro trabalhava bem.

Ex.: Marcia comprou farinha, ovos e leite. Foi para casa, ligou a batedeira, misturou os ingredientes e colocou-os no forno.

Maria fez um bolo.

Ao longo da explicação sobre objetividade, não chega a explicar como realizamos a estratégia de substituição, que abarca outros dois procedimentos, a saber: a generalização, que "consiste na substituição de uma série de nomes e seres, de propriedades e de ações por um nome de ser, propriedade ou ação mais geral", e a construção, que "consiste na substituição de uma sequência de proposições, expressas ou pressupostas, por uma proposição que é normalmente inferida delas, por meio da associação de seus significados" (MACHADO; LOUSADA; ABREU-TARDELLI, 2005, p.89). Estratégias essas essenciais para produção do gênero resumo, uma vez que permitem reduzir as ideias do texto e conservar apenas o essencial, e que, em nossa opinião, poderiam ter sido focalizadas nos módulos, se estes tivessem sido propostos.

Constatamos que vários saberes relacionados ao gênero são apresentados pelo professor, porém todas as informações foram expostas de uma única vez, não havendo a decomposição em etapas nem a comparação e análise de exemplos do gênero. O único exemplo proposto não correspondia a um texto autêntico, já que era um resumo de uma reportagem que foi utilizado como exemplo em um livro didático.

A seguir, vamos discutir mais especificamente a organização da sequência didática e refletir sobre a ausência de atividades e exercícios para tratar as dimensões do objeto durante a sequência de ensino implementada pelo professor.

\subsubsection{A organização da sequência de ensino implementada pelo professor}

Considerando a sequência de ensino implementada, percebemos que ela foge ao princípio teórico-metodológico da sequência didática proposta por Dolz, Noverraz e Schneuwly (2004) e isso traz implicações ao ensino e à aprendizagem. Assim, para fazer a análise da forma de apresentação e organização dos conteúdos da sequência de ensino realizada pelo docente, vamos nos apoiar no pressuposto de que o trabalho com gênero de texto, como objeto autônomo, precisa ser mediado pela ferramenta sequência didática, a qual se apoia nestes 
princípios: elaboração de um modelo didático, construção de módulos que tratem de aspectos necessários ao domínio do gênero-alvo e adoção de uma abordagem que parta da atividade linguageira complexa, passando pela decomposição das atividades em múltiplas dimensões, por meio de "tarefas diversificadas de análise, observação, reescrita e exercitação" (SCHNEUWLY; CORDEIRO, 2016, p. 92). Tudo isso com vistas à criação de situações que visem ao domínio do gênero.

Com base na observação das aulas, parece que falta uma compreensão do que significa trabalhar sobre o gênero e, sobretudo, o desconhecimento de como organizar atividades e propor tarefas ${ }^{6}$ orientadas para um mesmo objetivo. Evidencia-se haver dificuldade de se afastar do modelo expositivo, que se apoia no seguinte movimento didático: exposição do conteúdo e produção. Em suma, persiste ao que tudo indica a crença de que o aluno converte automaticamente o saber conceitual em saber procedimental.

Como os autores nos quais nos baseamos, entendemos que a atividade de produzir um texto precisa ser decomposta para ser possível abordar os diversos elementos que caracterizam, por exemplo, a produção do gênero resumo. E uma proposta metodológica que a viabiliza é a da sequência didática. Nas aulas observadas, houve a intenção de fazer uma, mas o professor não conseguiu seguir o movimento didático previsto nesse dispositivo, conforme destacam Dolz, Noverraz e Schneuwly (2004, p. 103), ou por não ter se apropriado dele durante sua formação inicial, ou por não ter tempo para realizar um bom planejamento.

O movimento geral da sequência didática vai [...] do complexo para o simples: da produção inicial aos módulos, cada um trabalhando uma ou outra capacidade necessária ao domínio de um gênero. No fim, o movimento leva novamente ao complexo: a produção final.

\footnotetext{
6 A tarefa constitui-se de um conjunto de enunciados de instrução que define o que será feito pelo aluno e foca as dimensões do objeto a ser estudado. Ela "operacionaliza e materializa os conteúdos de ensino; é definida pelo professor ou pelos elaboradores de programas e manuais; compõe-se de um problema que pressupõe uma resolução pelos alunos; está circunscrita dentro de um espaço e tempo determinados; tem um objetivo específico que se traduz em um resultado ou em umtproduto; pressupõe a implementação de um ou mais procedimentos (DOLZ et al., 2001, p. 3)
}

Assim, se considerarmos a estrutura: apresentação da situação, primeira produção, módulos e produção final, vemos que não houve um momento na aula em que o professor expusesse de maneira explícita o projeto comunicativo que seria realizado (exposição dos resumos no pátio dos alunos em varal) e possibilitasse o contato dos alunos com o gênero-alvo, por meio de exercícios e tarefas que os levassem a reconhecer os elementos da situação de comunicação e a ter uma visão clara da atividade de linguagem. $\mathrm{Na}$ proposta realizada, o aluno não teve a oportunidade de ler os textos-base e seus respectivos resumos para ter uma ideia do que vem a ser um texto do gênero resumo; além disso, não houve reflexão sobre o problema de comunicação; reflexão essa que poderia ter sido feita a partir destas perguntas: Qual é o gênero que vai ser abordado? Com que finalidade o texto será escrito? A quem a produção vai se destinar? Em que suporte o texto será publicado? entre outras. Esse trabalho poderia ter fornecido aos alunos todas as informações necessárias para que conhecessem o projeto comunicativo, como pontuam Dolz, Noverraz e Schneuwly (2004).

Ainda com base na estrutura da sequência, observamos que a primeira produção não foi seguida de um trabalho mais centrado em torno das dificuldades de escrita dos alunos. O professor identifica certos problemas nos textos, escreve notas nos textos dos alunos, mas não chega a propor atividades e exercícios que poderiam ser realizados ao longo dos módulos, de modo a ajustar a sequência às possibilidades e dificuldades reais dos alunos. Após o professor fazer certas correções e comentar alguns aspectos pontuados no texto de cada aluno, solicita que eles organizem o resumo para expor na aula seguinte. No trecho abaixo, percebemos o tipo de intervenção que é feito e, a partir dela, é que o aluno vai "reescrever" o texto.

Professor: Tá... eu vou lá depois... que você colocou no resumo... mas tá legal... PSI:: [chama um aluno]... vem aqui... O texto em si tá bom... eu quero que você traga ele na sexta-feira... eu venho buscar ele aqui... não dobra a página... eu quero ver ele (incompreensível) pode colocar uma imagem... PSI:: [chama outro aluno]... E:...... olha... coloca esse texto aqui na fonte treze... 
pode colocar uma imagem se tu quiseres... gostei do resumo... muito bom... só esse repetição aqui... pode colocar "o livro trata" é::.... "a história"... ok! Ficou bom o resumo... não dobra a página... tá!?

Se esses comentários fossem seguidos pela proposição de atividades e exercícios para tratar dos problemas que apareceram na primeira produção, os alunos teriam condições de melhorar o seu texto, mas infelizmente isso não ocorreu. Da produção inicial à final, os alunos ou descartaram o primeiro resumo produzido, substituindo por um resumo extraído da internet ou corrigiram a ortografia; ou ainda, retiraram ou acrescentaram alguma informação conforme a orientação do professor. A produção final, com base na qual 0 professor poderia avaliar se 0 aluno progrediu e se construiu conhecimentos acerca do gênero estudado, foi desconsiderada, uma vez que, após a correção da primeira produção, o texto final dos alunos foi exposto no mural, sem passar pela correção do professor. Dessa forma, ele não teve como fazer o balanço das aprendizagens nem os alunos tiveram oportunidade de observar suas aprendizagens.

No que diz respeito à variação das atividades e exercícios, não identificamos atividades de observação e de análise, propostas com vistas a pôr em evidência aspectos do funcionamento do texto (DOLZ; NOVERRAZ; SCHNEUWLY, 2004). Diante do que foi observado, como isso poderia ser feito pelo professor? Por meio da apresentação de textos e da comparação entre eles, levando o aluno a perceber os verbos utilizados, as informações que costumam aparecer no parágrafo introdutório etc. Esse trabalho poderia ter precedido a exposição dos conteúdos nos slides, momento que poderia ser apenas de generalização, de retomada dos conhecimentos trabalhados e construídos pelos alunos. Por meio da proposta de exercícios que trazem textos embaralhados e que solicitam aos alunos para reorganizá-los, com o objetivo de levá-los a compreender a estrutura do texto; não tendo sido esta explorada nas aulas pelo professor. Possivelmente, foi por isso que alguns alunos produziram textos argumentativos. Por meio da elaboração em conjunto com os alunos de uma ficha com as características comunicacionais, estruturais e linguísticas do gênero, a fim de auxiliar os alunos a produzirem e revisarem o seu resumo. Essas atividades e outras poderiam possibilitar que o aluno construísse um conhecimento mais sólido sobre o gênero e desenvolvesse uma atitude reflexiva sobre o próprio comportamento. Elas também poderiam favorecer a realização de um ensino orientado pela perspectiva vygotskiana, que tem como foco a superação das dificuldades. Nesse sentido, Dolz (2016, p. 246) afirma que a atividade compõe uma parte dos instrumentos do professor na ação de ensinar e visa a atingir alguns objetivos, tais como elencados abaixo:

1. Interagir com os obstáculos identificados, elementarizando a dificuldade de maneira a facilitar a apropriação de elementos novos (DOLZ; GAGNON; VUILLET, 2011).

2. Garantir a presença de dispositivos de apoio que facilitem as capacidades de linguagem do aluno.

3. Contribuir com uma explicação conceitual (BAUTIER; ROCHEX, 1997) e com uma compreensão das operações de linguagem mobilizadas pelo aluno para facilitar o desenvolvimento do controle consciente do comportamento verbal (SCHNEUWLY, 2008).

4. Fazer desaparecer progressivamente as ajudas externas até a devolução completa da tarefa para desenvolver autonomia do aluno.

5. Deixar um espaço de liberdade para o aluno que permita as interações e a construção subjetiva para converter-se em ator do seu próprio desenvolvimento da linguagem e da expressão de sua identidade.

Considerando o posicionamento de Dolz (2016) sobre as atividades e exercícios sobre gêneros textuais, reconhecemos que um dos principais obstáculos do professor investigado em realizar um trabalho, que pudesse viabilizar a superação das dificuldades dos alunos na produção escrita, foi não fazer a decomposição das atividades de linguagem em módulos, a fim de tratar aspectos do funcionamento do gênero, por meio de tarefas. O professor limitou a sequência a atividades complexas, isto é, focou apenas na produção do resumo. 
Assim, a partir da análise dos dados, ficou claro que o professor toma como objeto de ensino o gênero resumo, utilizando o método expositivo para apresentar as dimensões do objeto, como conteúdos, situação comunicativa e linguagem, não se valendo de atividades e tarefas para apoiar os alunos na superação das dificuldades encontradas durante a produção do texto. Apenas as notas e os comentários dele não foram suficientes para que os alunos reescrevessem o texto, ultrapassando os obstáculos iniciais, já que muitos elaboraram textos opinativos, outros continuaram a não mencionar, por exemplo, o autor e o tema do livro; e houve ainda aqueles que copiaram outro resumo da internet, não corrigindo a sua primeira produção, como a análise dos textos demonstrou.

\section{Considerações finais}

Nesta pesquisa, analisamos o trabalho de um professor específico em torno do ensino do gênero resumo. Para tanto, baseamo-nos nas discussões sobre gênero e o ensino da escrita. A pesquisa teve como objetivo geral verificar que dispositivo de ensino foi implementado pelo professor, quais dimensões do gênero foram ensinadas nas aulas do gênero resumo e que metodologia foi acionada na didatização do gênero.

Não há de se negar que o professor fez uma tentativa válida de ensino do gênero resumo. Entretanto, ele não se valeu do conhecimento das capacidades de linguagem dos alunos para ajustar suas intervenções, a fim de promover novas aprendizagens nem forneceu instrumentos para eles progredirem, porque, após a primeira produção e correção, ele não propôs atividades e exercícios que levassem o aluno a superar suas dificuldades iniciais. Sobre o trabalho dele, destacamos, considerando as reflexões de Pasquier e Dolz (2002), que alguns princípios, se tivessem sido seguidos, poderiam ter fomentado a aprendizagem do gênero resumo, são eles: o método indutivo; a regulação interna e externa; e a sequência didática. Um ensino orientado pelo método indutivo poderia ter permitido ao professor conduzir e orientar os alunos na descoberta de saberes e no desenvolvimento de habilidades para a produção escrita e Ihes permitir tomar consciência do funcionamento linguístico, a partir de observações e análises. Por meio da realização de regulação interna e externa, o professor poderia ter utilizado instrumentos de regulação externos, como uma grade avaliativa contendo as características do gênero, para auxiliar os alunos na reescrita do texto, e ter criado a oportunidade de esses instrumentos se tornarem meios de regulação interna. O uso do dispositivo sequência didática poderia ter favorecido a identificação das dificuldades dos alunos e o tratamento dos problemas identificados, o que viabilizaria a tomada de consciência dos alunos quanto ao seu desenvolvimento. Diferente da sequência didática (DOLZ; NOVERRAZ; SCHNEUWLY, 2004), o professor mobilizou um dispositivo que previa apenas a exposição do conteúdo (apoiada em slides), a produção inicial e a "reescrita", que não se caracterizou de fato como tal, como observamos ao compararmos os textos da primeira produção e da última.

De modo geral, nossa intenção com este artigo foi problematizar como a ordem e a hierarquia de atividades propostas no interior de uma sequência de ensino podem favorecer a aprendizagem do aluno, quando feitas de forma explícita e sistemática, e como sua ausência pode prejudicar tanto o ensino quanto a aprendizagem.

Terminamos destacando que a entrada do ensino de gêneros na escola representa um avanço, considerando, principalmente, um sistema educacional que vive em função do Enem, cujo foco é o texto argumentativo-dissertativo. Contudo, essa introdução não é suficiente para o desenvolvimento das capacidades de ação linguística e linguísticadiscursiva dos alunos, apenas indicando uma mudança de objeto de ensino. O que fazer então para modificar esse quadro?

É necessário mudanças nos métodos. Percebemos que o professor investigado se empenha em apresentar os conteúdos referentes ao gênero resumo, mas o faz de forma expositiva, não fazendo a adaptação didática que cada gênero de texto exige. 
Faltou adotar uma metodologia adequada, que permitisse focar os saberes que iriam apoiar a produção escrita, de forma ordenada e sequencial e que lançasse mão de atividades e exercícios para envolver os alunos no processo de aprendizagem.

Diante disso, sugerimos que sejam feitas pesquisas que tratem da elaboração de instrumentos didáticos que adotem princípios teóricometodológicos que favoreçam a criação de atividades e exercícios de observação, análise e construção de saberes. Pensamos também que os currículos de formação de professores de língua portuguesa precisam se revistos, para que os estudantes de Letras reconheçam e compreendam que o professor tem uma responsabilidade muito grande na construção dos objetos ensinados, como destacam Dolz, Jacquin e Schneuwly (2006, p. 146, tradução nossa):

O objeto ensinado se apresenta assim como 0 resultado do trabalho do professor em função dos alunos em uma situação dada. Esse trabalho torna 0 objeto presente em sala de aula e mostra as dimensões a aprender graças à construção de situações e dispositivos didáticos que definem as atividades escolares [...].

\section{Referências}

ANTUNES, I. Aula de Português: encontro e interação. São Paulo: Parábola, 2003.

BAKHTIN, M. Estética da criação verbal. São Paulo: Martins Fontes, 1997.

BRASIL. Secretaria de Educação Fundamental. Parâmetros curriculares nacionais: terceiro e quarto ciclos do ensino fundamental: Língua Portuguesa. Brasília: MEC/SEF, 1998.

BRASIL, MINISTÉRIO DA EDUCAÇÃO. Base nacional comum curricular. MEC/SEF, 2017.

BRONCKART, J-P. Atividades de linguagem, textos e discursos: por um interacionismo sociodiscursivo.
Tradução de Anna Rachel Machado e Péricles Cunha. 2. ed. São Paulo: EDUC, 2007.

DE PIETRO, J-F; SCHNEUWLY, B. O modelo didático do gênero: um conceito da engenharia didática. MOARA: revista da pós-graduação em letras da UFPA. Belém: CLA/UFPA, n. 25, p. 1552, jan./ jun. 2006.

DOLZ, J. As atividades e os exercícios de língua: uma reflexão sobre a engenharia didática. D.E.L.T.A., São Paulo, n. 32, p. 237-260, 2016.

DOLZ, J.; JACQUIN, M.; SCHNEUWLY, B. Le curriculum enseigné en classe de français au secondaire: une approche à traves des objets enseignés. In : AUDIGIER, F. ; CRAHAY, M. ; DOLZ, J. Curriculum, enseignement et pilotage. Bruxelas: De Boeck \& Larcier s.a, 2006. p. 143164.

DOLZ, J.; NOVERRAZ, M.: SCHNEUWLY, B. Sequências didáticas para o oral e a escrita: apresentação de um procedimento. In: SCHNEUWLY, B.; DOLZ, J. Gêneros orais e escritos na escola. Campinas, SP: Mercado de Letras, 2004, p. 81-108.

DOLZ, J.; SCHNEUWLY, B.; HALLER, S. O oral como texto: como construir um objeto de ensino. In: In: SCHNEUWLY, B.; DOLZ, J. Gêneros orais e escritos na escola. Campinas, SP: Mercado de Letras, 2004, p.149-185.

DOLZ, J. ; SCHNEUWLY, B. Pour un enseignement de l'oral: Initiation aux genres formels à l'école. Paris, ESF éditeur, 1998.

FIORIN, J. L. Introdução ao pensamento de Bakhtin. São Paulo: Ática, 2006.

GERALDI, J.W. Da redação à produção de textos. In: GERALDI, J.W.; CITELLI, B. (Orgs.). Aprender e ensinar com textos de alunos. v. 1. São Paulo: Cortez, 1997. 
GIL, A. C. Métodos e técnicas de pesquisa social. 5. ed. São Paulo: Atlas, 2010.

GODOY, A. S. Introdução à pesquisa qualitativa e suas possibilidades. Revista de Administração de Empresas/ EASP/ FGV. São Paulo, v. 35, n.2, p. 57-63, mar./abr. 1995.

GOMES-SANTOS, S. N.; SEIXAS, C. Gêneros textuais da formação docente inicial: o projeto de ensino de língua portuguesa. SCRIPTA, Belo Horizonte, v. 16, n. 30, p. 151-168, 1 sem. 2012. Disponível em: $<$ http://periodicos.pucminas.br/index.php/scripta/ar ticle/view/4245/4398>. Acesso em: 15 jan. 2017.

GUIMARÃES, A. M. de M. Construindo propostas de didatização de gênero: desafios e possibilidades. Linguagem em (Dis)curso - LemD, Tubarão, v. 6, n. 3, p. 347-374, set./dez. 2006.

LUDKE, M.; ANDRÉ, M. E .D. A. Pesquisa em educação: abordagens qualitativas. São Paulo:Editora Pedagógica e Universitária, 1986.

MACHADO, A. R.; LOUSADA, E.; ABREUTARDELLI, L. S. O resumo escolar: uma proposta de ensino do gênero. SIGNUM: Estud. Ling., Londrina, n. 8, p. 89-101, jun. 2005.

MARCUSCHI, B. Escrevendo na escola para a vida. In: RANGEL, E. O.; ROJO, R. H. (Orgs.) Coleção explorando o ensino: Língua Portuguesa. Brasília: MEC, Secretaria de Educação Básica, 2010. Disponível em: $<$ http://dediadema.edunet.sp.gov.br>. Acesso em: 15 jan. 2018.
NASCIMENTO, E. L.; GONÇALVES, A. V.; SAITO, C. L. N. Gêneros textuais e ferramentas didáticas para a formação contínua de professores de língua portuguesa. SIGNUM: Estud. Ling., Londrina, n.10/2, p. 89-112, dez. 2007.

PASQUIER, A.; DOLZ, J. Um decálogo para ensinar a escrever. Tradução de Roxane Helena Rodrigues Rojo. In: PEC - Formação Universitária. São Paulo: Secretaria da Educação/PUC/USP/UNESP, 2002.

ROJO, R. H. R. Modelização didática e planejamento: Duas práticas esquecidas do professor?. In: Ângela B. Kleiman. (Org.). A Formação do Professor: Perspectivas da Linguística Aplicada. São Paulo: Mercado de Letras, 2001, p. 313-335.

SCHNEUWLY, B. Palavra e ficcionalização: um caminho para o ensino da linguagem oral. In: Gêneros orais e escritos na escola. Tradução de Roxane Rojo e Glaís Sales Cordeiro. São Paulo: Mercado de Letras, 2004, p. 129-147.

SCHNEUWLY, B; DOLZ, J. Gêneros orais e escritos na escola. Tradução de Roxane Rojo e Glaís Sales Cordeiro. São Paulo: Mercado de Letras, 2004.

SCHNEUWLY, B.; CORDEIRO, G. S. Le genre de texte comme objet autonome d'enseignement: comparaison de deux approches didactiques. In : CORDEIRO, G. S; VRYDAGHS, D. Status des genres en didactique du français. Bélgica: Presses Universitaires de Namur, 2016, p. 83-108.

\section{COMO CITAR ESSE ARTIGO}

OLIVEIRA, Márcia Andréa Almeida de; COSTA, Luana Aquino da. OS SABERES ENSINADOS NAS AULAS DE PRODUÇÃO DO GÊNERO RESUMO. Signo, Santa Cruz do Sul, v. 43, n. 77, jul. 2018. ISSN $1982-2014$. Disponível em: <https://online.unisc.br/seer/index.php/signo/article/view/11806>. Acesso em: doi:http://dx.doi.org/10.17058/signo.v43i77.11806..

MARTINAND, J-L. Connaître et transformer la

matière. Berne: Peter Lang, 1986. 